\title{
Sensemaking in the Legal System: A Comparative Case Study of Changes to Monetary Sanction Laws
}

\author{
TYLER SMITH, KRISTINA J. THOMPSON, AND MICHELE CADIGAN(
}

Legal scholars have long studied why laws are implemented differently across local court contexts. Key to understanding this localized variation is understanding how new laws are communicated, interpreted, and negotiated within the legal field. Few studies, however, have directly examined the process by which court actors interpret and negotiate new laws within the court. We explore these sensemaking processes through interviews and observations of court actors in Washington and Missouri after changes to monetary sanction laws. We identify three primary forms of sensemaking and analyze contextual factors that shape these processes. We find key differences in sensemaking based on differing levels of regulatory oversight but also that normative and cultural factors were still important in determining legal interpretation and implementation within each state. These findings have important implications for our theoretical understanding of courtroom communities and for policymakers seeking to enact reform.

Keywords: legal change, monetary sanctions, courtroom communities

Local variation in the implementation of legal mandates and policy guidelines is a consistent theme in the study of criminal courts (Myers and Talarico 1987; Dixon 1995; Engen and Steen 2000; Kirk et al. 2022, this volume; Stewart et al. 2022, this volume). Much of this research emphasizes the courtroom as a field where representatives from different judicial occupations and sponsoring agencies interact in the common workspace of the court. Through interaction, negotiation, and conflict resolution, these courtroom communities develop their own localized norms that guide court actor behavior (Flemming, Nardulli, and Eisenstein 1992). When new laws are enacted, their implementation is not only affected by the institutional

Tyler Smith and Michele Cadigan are Ph.D. students of sociology at the University of Washington, United States. Kristina J. Thompson is an assistant professor of Criminal Justice and Criminology at Georgia Southern University, United States.

(C) 2022 Russell Sage Foundation. Smith, Tyler, Kristina J. Thompson, and Michele Cadigan. 2022. “Sensemaking in the Legal System: A Comparative Case Study of Changes to Monetary Sanction Laws." RSF: The Russell Sage Foundation Journal of the Social Sciences 8(1): 63-81. DOI: 10.7758/RSF.2022.8.1.03. We would like to thank Arnold Ventures for providing funding for this project (PI: Alexes Harris) and the Multi-State Monetary Sanctions Study team and research assistants who contributed to the data collection process. Partial support for this research came from a Eunice Kennedy Shriver National Institute of Child Health and Human Development research infrastructure grant, P2C HD042828, to the Center for Studies in Demography and Ecology at the University of Washington. Direct correspondence to: Tyler Smith, at tjsmith1@uw.edu, 211 Savery Hall, Box 353340, Seattle, WA 98195-3340, United States.

Open Access Policy: RSF: The Russell Sage Foundation Journal of the Social Sciences is an open access journal. This article is published under a Creative Commons Attribution-NonCommercial-NoDerivs 3.0 Unported License. 
context in which they are passed, but also filtered through established and localized "processural orders" (Strauss 1993; Ulmer 2005). Unpacking the interplay between lawful mandates and the contexts in which they are applied is critical because the resultant change in courtroom practice within any given jurisdiction may or may not align with the proposed goals of legal changes.

Recently, scholars have begun to critically examine the process by which laws are interpreted and negotiated between court actors (Clair 2020; Johnson 2005; Van Cleave 2020). Such interactive work is especially important after changes in the law, when court actors must engage in shared decision-making in order to implement new courtroom procedures. We agree with Jeffery Ulmer (2019) in thinking of courts as inhabited institutions, which is a concept that characterizes legal establishments as "inhabited" by organizational actors that use their agency to interpret and react to institutional pressures and organizational demands. Ulmer further suggests that we align this perspective with the literature on courtroom communities, which emphasizes how individuals from different professional agencies interact in the courtroom field. Local court practices arise through the interaction of court actors as their different interpretations of policies are negotiated, contested, and resolved. In addition, how these interactions and negotiations play out is shaped by a nested set of contextual and organizational dimensions (Scott 2008).

One of the major tasks under this perspective is to better understand the processes by which conformity develops both across and within local courtroom communities. Organizational researchers have long studied isomorphic processes, but understanding how these processes operate within the criminal justice system requires a ground-level examination of courtroom sensemaking. Even though new laws and guidelines are ordered from the top down, implementation of new procedures hinges on the formal and informal characteristics of each court's local culture, norms of interaction, and structural embeddedness.

Drawing on interviews and courtroom observations, we explored the mechanisms of legal interpretation and change based on changes to monetary sanction laws (also known as legal financial obligations, or LFOs) in Missouri and Washington State. Given our fortunate placement in the field during or soon after changes in the law, we were able to capture how information about these laws were diffused within local court systems, how court actors oriented themselves toward these changes, and how they engaged in discussion, negotiation, and contestation with other court actors in relation to necessary changes in practice. We identified three distinct forms of meaning-making in our field sites: collaborative interpretation, when courtroom decision-makers met with the explicit purpose of interpreting legal changes; contested negotiation, in which court actors disagreed on either how to interpret the new law or how to put the new law into practice; and passive acceptance, when court actors in one profession deferred to court actors in another profession or adapted their behaviors to maintain the dominant processual order.

We also outline contextual features that shaped how these meaning-making processes played out. Of particular importance was the different regulatory frameworks across the states. Courts in Missouri were given a greater degree of regulatory guidance, which ensured that courts across jurisdictions engaged in greater levels of collaborative sensemaking and congruence with the new laws. However, the differing legal structures of the two states was not wholly determinant and the effectiveness of regulation was still mitigated by several other factors. Transitioning to new courtroom practices was more or less effective depending on how the new laws aligned with local court cultures, previous policies, and the realities of case processing. In addition, the professional siloing of courtroom communities limited opportunities for sensemaking across professional boundaries in nearly every jurisdiction in our study. So, although increased regulative pressure in Missouri seemed to increase understanding of new laws and induced a higher degree of conformity across courts compared to Washington, it was not a panacea.

Whether court actors passively accepted, collaboratively interpreted, or contested and negotiated legal actions depended on a variety of local and state-level factors that included the 
extent of oversight and guidance from regulatory agencies, the organizational structure of courtroom communities, existing local processual orders, and the ideological orientation of the courts. ${ }^{1}$ Overall, we contribute to understandings of local conformity and variation in practice by applying Ulmer's framework and identifying circumstances that lead to laws being differentially applied across courts.

\section{COURTS AS INHABITED INSTITUTIONS}

A key concern for all criminal justice systems is the uniform application of legal mandates and sentencing guidelines. However, researchers consistently demonstrate court by court variation in the implementation of formally mandated practices at both the federal (Spohn and Fornango 2009; Ulmer and Johnson 2017) and state levels (Hester 2017; Ulmer 2012). Understanding why these guideline departures occur is an important and robust area of theoretical and empirical examination.

To understand conformity and difference across courts, Ulmer (2019) suggests viewing court systems as inhabited institutions. ${ }^{2}$ This approach combines insights from legal and organizational scholarship by emphasizing both the interactive process between court actors and the larger social context in which they are embedded. By conceptualizing court systems as institutional fields, we can study how court actors "interact with knowledge of one another under a set of common understandings for the purpose of the field, the relationships in the field, and the field's rules" (Fligstein and McAdam 2011, 3). Such a framework allows us to borrow insights from organizational research that can help us understand the broader influences that impact court systems.
Expanding on the foundational work of Paul DiMaggio and Walter Powell (1983), Richard Scott (2008) suggests three primary types of influences that shape institutional fields. First are regulative influences that attempt to outline accepted behavior, establish expectations, and administer sanctions. Conceptions of regulatory power often center on the ability of administrative bodies to use coercion to enforce conformity to specific guidelines. This kind of coercive influence is an important part of the legal field, given that regulatory bodies attempt to ensure the uniform application of the law. However, regulatory influences may also enable and empower individuals by "conferring licenses, special powers, and benefits to some types of actors" (Scott 2008, 61). Certain actors may be given special legal authority within a given social space that allows them to dictate daily activities and enforce their conceptions of expected behavior.

The second type of influence develops from normative pressures that produce action based on the perceived norms of the field and ideas of legitimacy. Normative systems can be broken into two main components. Values designate the legitimate or accepted motivations behind organizational action, generally in accordance to "macro-myths" that define the reasoning behind institutional practices (Meyer and Rowan 1977). For the criminal justice system, these include ideas about justice, due process, and equality before the law. Norms refer to behaviors that are considered to be the correct or appropriate methods for achieving alignment with these values. Many normative actions within court systems can be thought of as attempts to align with local logics about the proper purpose

1. Such findings align with recent explorations of the tension between jurisprudence and the practicalities of courtrooms. Franklin Zimring (2020), for example, argues that efforts to change sentencing outcomes (mass incarceration) could be more successful if they identified and altered the power dynamics that shape sentencing practices.

2. A pair of articles in this volume offer additional theoretical discussion about how the inhabited institutions perspective may be used to understand monetary sanctions. In one, Karin Martin, Kimberly Spencer-Suarez, and Gabriela Kirk (2022) use this framework to understand local norms around accountability. They find that these norms often require defendants to engage in performances of accountability and lead to the discretionary use of time as punishment. In the other, Kirk and her colleagues (2022) explore local acquaintanceship density as an important factor in the interactive process between court actors and those involved in the criminal justice system. 
of criminal justice and the roles of the actors within the system.

The final type of influence on court systems comes from cultural-cognitive factors. These represent the shared meanings and social frameworks that actors within a given field adopt. Such dimensions operate across nested levels-including the subjective interpretation of signs and symbols by individuals, the creation of collective understandings through interactive creation of field-level rules and practices, and the crystalized beliefs and ideologies that make up larger cultural frameworks (Berger and Kelner 1981; DiMaggio and Powell 1983). Understanding these cultural-cognitive factors helps us recognize often overlooked factors that determine organizational action. In addition to being dictated by coercive forces and guided by repetitive norms, specific behaviors are often based around the legitimacy that comes from conforming to common definitions, actor roles, and organizational templates (Scott 2008, 74). Here we may think of the operational structure of courts and how that structure aligns with broader ideals of justice as accepted cultural frameworks for understanding criminal justice systems.

It is important to consider these factors as they operate within the unique structure of U.S. courts as outlined by the court community framework (Eisenstein, Flemming, and Nardulli 1988). A courtroom community can be thought of as the combined efforts of representatives from different sponsoring agencies who interact within the shared, common workspace of the court to create local court cultures. ${ }^{3}$ Broadening this conception of court communities using organizational theories offers important addendums to the court community perspective. It allows us to understand court systems as "inhabited" by individual agents who "constantly interpret and make sense of rules and formal structures" in accordance with the organizational expectations of their sponsoring agencies and their own personal understandings of courtroom rules and expec- tations (Ulmer 2019, 484). As individuals engage with each other in strategic interactions during their daily work, they are constantly producing, maintaining, and transforming localized court norms and common cultural expectations (Kirk et al. 2022, this volume; Strauss 1993). These processes not only shape local practices but are also consequential for citizens involved in the criminal justice system. Evidence from Missouri demonstrates how local economic and political priorities influence the application of low-level justice (Huebner and Giuffre 2022). This dynamic, interactive process is thus an essential and consequential component of variation within and across court systems.

An organizational framework also calls for us to explore the interactive effect of field-level factors at various levels. The sensemaking process itself is directly shaped by the other influential factors that exist within that given organizational space. We are also reminded that court communities exist within an even larger set of nested institutional fields and that the regulative, normative, and cultural-cognitive influences of these contexts are important variables in understanding courtroom practice. Considering the importance of sensemaking in the creation of localized practice, it is essential that scholars understand the specific sensemaking processes that occur in the legal field and the potential contextual factors that shape them.

\section{SENSEMAKING AFTER LEGAL CHANGE}

Changes to the law that require changes to courtroom practice introduce essential moments of sensemaking that can help us understand local guideline departures. Regulatory action that attempts to change courtroom behavior is an important form of coercive influence on court system functioning. However, these changes must be implemented by the actors within a given court system with its own set of norms and cultural expectations. Changes in the law must go through the inter- 
active sensemaking process by which all activity within the field of the court system is interpreted, negotiated, and crystallized from the outcomes of previous strategic interaction (Berger and Luckmann 1967). The introduction of new rules and regulations, or laws that alter previous practices, disturbs the established normative order of the court and requires a new set of agreed-upon rules for behavior and interaction. As Ulmer explains, "Informal norms and arrangements often emerge as negotiated solutions to problems not covered by existing rules, ambiguous or conflicting goals, or conflicts over resources. These solutions persist until challenging new situations render them inadequate. Then, new negotiation processes occur through which informal arrangements are adapted in an attempt to resolve the new problems" (2019, 90).

Although we have made the importance of this sensemaking process clear, the process is difficult to examine directly. Further, few studies examine the process of sensemaking during a transition in practice after legal change. Many studies of guideline departures are quantitative comparisons of case processing outcomes or look at guideline departures after new guidelines have been established for some time (Johnson 2005; Ulmer and Johnson 2004). In addition, although some of these studies examine larger contextual factors (Hester 2017), they do not adequately show how these factors affect the sensemaking process itself. A more robust study requires a closer inspection of actor interaction, negotiation, contestation, and acceptance during the period court actors are actively trying to put new laws into practice.

In this article, we theorize about the dynamics and structure of the sensemaking processes that court actors engaged in after changes to monetary sanction laws and outline some of the important regulative, normative, and cultural-cognitive dynamics that shaped, hindered, or facilitated this process. Drawing on in-depth interviews with court actors and thick descriptions of courtroom procedures from our ethnographic fieldwork in Washington State and Missouri, we contribute to the literature in two key ways. First, we outline the qualitative aspects of the sensemaking process itself. We observed three types of interactive sensemaking that were common to our sites and identified where and when they occurred in the court process. Second, we outline the contextual factors that shaped these processes, including how aspects of each state's legal system impacted perceptions and receptivity to change, how the court's organizational structure shaped sensemaking opportunities, and how larger cultural and institutional factors helped or hindered efforts to produce court-wide conformity. Overall, we provide a deep examination into the influences that shape local courtroom practice.

\section{DATA AND METHODS}

While we conducted field work in Missouri and Washington, both states experienced reform efforts aimed at redesigning their monetary sanction systems. This offered us a unique opportunity to explore how court actors discussed their ongoing attempts at making sense of the new laws and how they negotiated their interpretations. It also allowed us to directly observe instances of sensemaking in the courtroom more clearly, given that the new policies were not fully routinized (or still subject to multiple interpretations) in many of our court sites.

The most significant and publicized legislative change in Missouri was Mack's Creek Law, ${ }^{4}$ which was passed in direct response to the police killing of Michael Brown and subsequent Justice Department investigation of the city of Ferguson. The primary focus of the law was to limit the amount of money that municipalities could raise for their general revenue through fines, bond forfeitures, and fees. ${ }^{5}$ The key text capped the amount of money generated from ticketing and fines at 20 percent when it had

4. Missouri Senate Bill CCS/HCS/SS/SCS/SB 5 (2015), https://www.senate.mo.gov/15info/BTS_Web /Bill.aspx?SessionType=R\&BillID=160 (accessed August 20, 2021).

5. For further discussion of the consequences of municipal regulations (or lack thereof), when combined with strong incentives to use low-level sanctions as a revenue source, see Huebner and Giuffre 2022, this volume. 
previously been 30 percent, ${ }^{6}$ and the total dollar amount for combined fines and fees for each individual could not exceed specified amounts depending on the number of violations. ${ }^{7} \mathrm{Fi}-$ nally, this legislative mandate reiterated that defendants cannot be jailed for failure to pay at the municipal level. In addition to changes in how LFOs were to be imposed and collected in Missouri, one of the core issues this new legislation dealt with was previously low oversight of municipal courts. Implementation was thus paired with significant oversight from Missouri's Office of State Court Administrators (OSCA), which provided bench cards that showed the expected dollar amounts for each type of case and facilitated annual conferences to educate and train court members.

Changes to monetary sanction laws in Washington State resulted from the 2013 court ruling in State of Washington v. Blazina. The Washington State Supreme Court ruled that local courts must make an individualized inquiry into a defendant's current and future ability to pay before imposing discretionary LFOs. ${ }^{8}$ If it is determined that a defendant does not have the ability to meet his or her financial obligations, judges must waive nonmandatory fines and fees. These rules were clarified further during our data collection in State of Washington $v$. Ramirez in 2018. ${ }^{9}$ Additionally, the Washington legislature passed House Bill 1783 in the spring of $2018 .{ }^{10} \mathrm{HB} 1783$ modified many of the existing rules and guidelines for determining ability to pay, assessing willful nonpayment, and attempted to clarify which fees were mandatory.
HB 1783 mandated that judges use the state's poverty guidelines in determining ability to pay assessments and judges must allow indigent individuals to set up reasonable payment plans. It also clarified that individuals could not be jailed for nonwillful nonpayment of their LFOs and that determinations of willful nonpayment must be based on current and future ability to pay.

\section{ANALYSIS}

To investigate the sensemaking process of legal practitioners, we drew on eighty-five semistructured interviews with key decision-makers and 391 hours of ethnographic observations within fourteen jurisdictions in Washington State and Missouri collected in 2018 and 2019. Jurisdictions selected for the study represented a range of rural, urban, and suburban court systems within each state that handled a variety of offenses ranging from misdemeanor and traffic cases to felonies.

The data used for this project were collected as part of the Multi-State Study of Monetary Sanctions, which examined the system of monetary sanctions across eight U.S. states. ${ }^{11} \mathrm{Al}-$ though the broader purpose of the project focused on understanding the assessment of legal debt and the experiences of those burdened with this debt, discussion around recent legal changes emerged as themes within our selected states. We leveraged this fact to better theorize how legal change is interpreted and implemented in real time within local court systems.

6. Municipalities operating in the St. Louis County area were initially capped at 12.5 percent, but this different standard was struck down in City of Normandy et al. v. Greitens et al., No. SC95624 (2017).

7. $\$ 225$ for a minor traffic violation, $\$ 275$ for a first or second municipal violation, $\$ 350$ for a third violation, and $\$ 450$ for any further violations within a twelve-month span.

8. State of Washington v. Blazina, No. 89028-5 (May 2013).

9. State of Washington v. Ramirez, No. 95249-3 (September 2018). This ruling requires judges to make specific inquiries when determining ability to pay, including assessments of income, debts, assets, living expenses, employment history, indigency status, and whether they will be incarcerated. The decision also clarified that these inquiries must be made on the record to be considered a sufficient examination.

10. Washington State House Bill 1783 (2018), https://app.leg.wa.gov/billsummary?BillNumber=1783\&Year=2017 (accessed August 20, 2021).

11. For further information about the methods of the broader project, how jurisdictions were selected, and sampling processes, see Harris, Pattillo, and Sykes 2022, this volume. 
Table 1. Court Actor Type by State

\begin{tabular}{lcc}
\hline Court Actor & Missouri $(\mathrm{N}=47)$ & Washington $(\mathrm{N}=38)$ \\
\hline Defense attorney & 8 & 15 \\
Prosecutor & 4 & 9 \\
Judge & 13 & 9 \\
Court clerk & 9 & 3 \\
Community supervision officer & 12 & 2 \\
Other & 1 & N/A \\
Hours of courtroom observation & 93 & 106
\end{tabular}

Source: Authors' calculations

Semi-structured interviews with courtroom decision-makers included prosecutors, defense attorneys, judges, court clerks, and community supervision officers (see table 1). Respondents were asked a series of questions about local court norms regarding assessing and imposing monetary sanctions, the process for recouping unpaid debt, how willful noncompliance is determined, the function of LFOs more broadly, and their experience with any changes in laws regarding monetary sanctions. Responses to these questions were transcribed by an external professional transcription service and uploaded to a secure server.

The transcripts were then coded by a trained team of researchers using a uniformed code book of topical codes that was applied to all decision-maker interviews across all field sites that were part of the larger study. From these broader codes, we engaged in more targeted analytic coding of themes related to sensemaking and legal change. Our analytic coding followed the process of identifying and coding text for the purpose of interpreting emergent themes, reflecting on members' meanings, and generating explanations or ideas about the data (Richards 2015). Specifically, we closely examined all data coded at topical codes that examined court culture, local and state politics, discussion of the legal system, the process of imposing LFOs, and decision-maker experiences and opinions about the laws governing LFOs (see table 2).

From this analytic coding, we identified three common pathways through which local court actors engaged in sensemaking to implement new laws - passive acceptance, contested negotiation, and collaborative interpretation.
We constructed analytic memos (see Emerson, Fretz, and Shaw 2011) for how each sensemaking process occurred in each state and what factors affected how that process functioned. Once these memos were complete, we met to discuss and refine our definition of these approaches based on the data.

To understand what shaped court actors' approach to interpreting and implementing legal changes, we engaged in another round of analytic memoing in which we identified the approaches used in each jurisdiction and type of court actor using this strategy. We then compared these approaches across jurisdictions and states, paying particular attention to where strategies diverged within or across jurisdictions and professions. We noted any contextual factors that appeared to be associated with particular approaches and identified several mechanisms that emerged as important for facilitating particular pathways.

\section{FINDINGS}

Broadly, we identified three processes that decision-makers used when interpreting legal changes and implementing them in courtroom practices. Actors engaged in collaborative interpretation when they came together to discuss, interpret, and make sense of legal changes in a collaborative way. Discussions centered around both formal policies that had to be implemented and how new laws would affect informal or localized changes to practice. These collaborative circumstances were particularly common among judges and often achieved through established methods of communication at the local level (such as scheduled judges meetings) and state level (such as statewide 
Table 2. Topical Codes Used for Analytic Coding

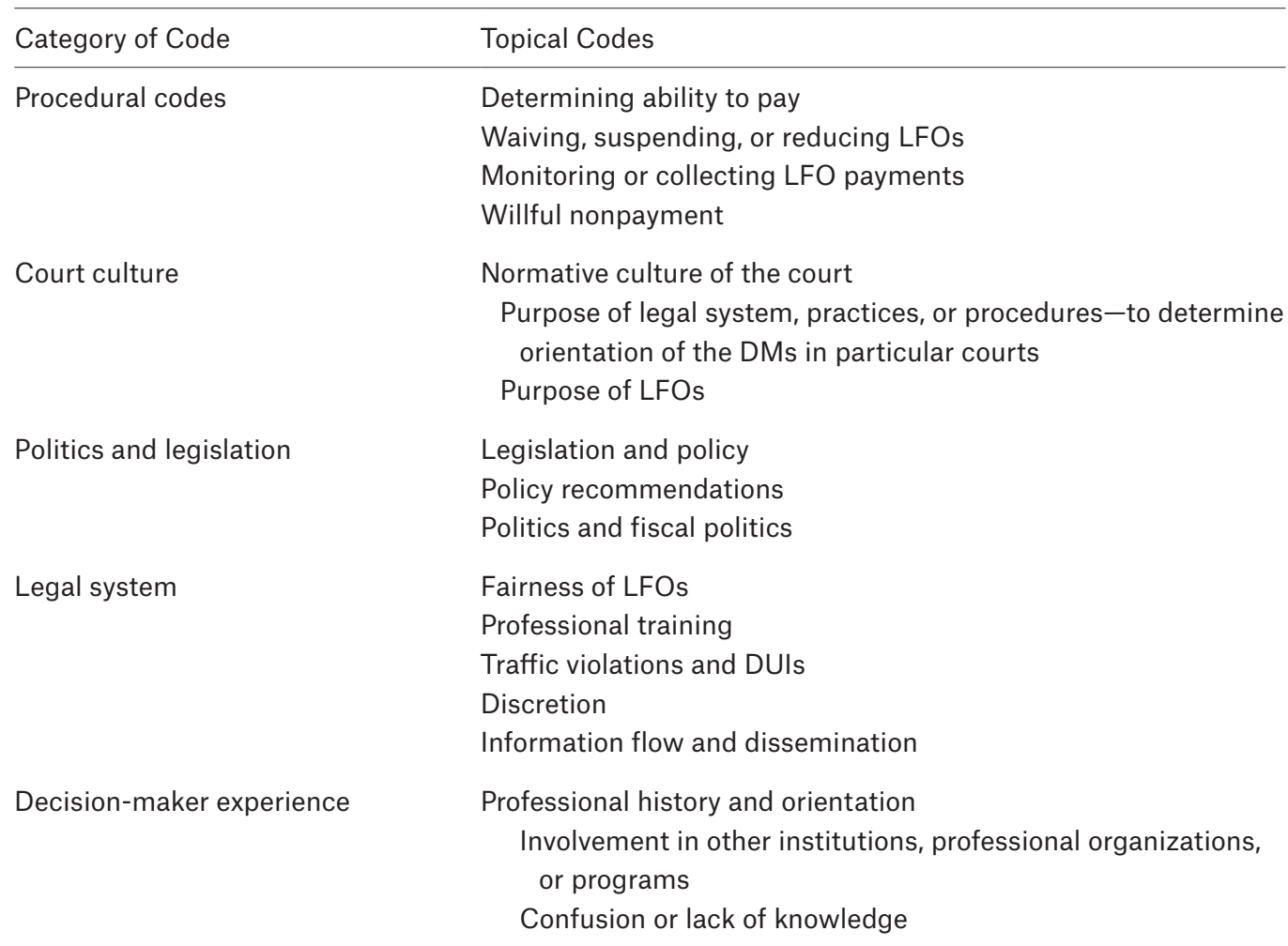

Source: Authors' tabulation.

judges conferences). Court actors also engaged in informal means of collaboration, such as defense attorneys meeting with prosecutors outside of court, although this appeared to be a rare occurrence. The important aspect of collaborative interpretation was available space for discussing legal changes as a group, not necessarily achieving consensus. Even if consensus was not reached through this collaborative work, individual decision-makers came away from the process with a better understanding of how other members of their profession or larger courtroom community understood and implemented the new laws.

Another type of active sensemaking occurred through instances of contested negotiations. These were times when decision-makers disagreed on either how to interpret changes in law or how to put these changes into practice and action was taken to contest different attempts at implementation in the courtroom. We found that these disagreements related to the interpretation of the legal mandates them- selves as well as disagreements on how specific courtroom practices were put in place. Although disagreements would sometimes arise during courtroom proceedings, the most obvious forms of contestation were formal channels outside court. For example, contested negotiation often occurred during plea agreements between attorneys when one attorney would not yield to the other's interpretation of new legal mandates or in the filing of legal briefs written by defense attorneys trying to get judges to align their understanding of the new laws with their own interpretations. This yielded changes to normative practices as otherwise predictable processes of the courtroom became contested and drawn out.

The third type of sensemaking we observed were forms of passive acceptance. Passive acceptance occurred when decision-makers did not make explicit attempts at interpreting or understanding legal changes. Instead, court actors deferred to other individuals to interpret and apply legal changes or adapted their behav- 
Table 3. Summary of Key Findings

\begin{tabular}{|c|c|c|c|}
\hline \multirow{2}{*}{$\begin{array}{l}\text { Sense-making } \\
\text { outcomes }\end{array}$} & \multicolumn{3}{|c|}{ Institutional Influences (Scott, 2008) } \\
\hline & Regulative & Normative & Cultural-cognitive \\
\hline \multirow{2}{*}{$\begin{array}{l}\text { Passive } \\
\text { acceptance }\end{array}$} & Regulatory oversight (+) & Court efficiency macro-myths (+) & \multirow{2}{*}{$\begin{array}{l}\text { Siloed court } \\
\text { communities }(+)\end{array}$} \\
\hline & Legal ambiguity (-) & $\begin{array}{l}\text { Conflicting assumptions of } \\
\text { decision-making power } \\
\text { [moderates court-efficiency } \\
\text { pathway }(-)]\end{array}$ & \\
\hline $\begin{array}{l}\text { Collaborative } \\
\text { interpretation }\end{array}$ & Regulatory oversight (+) & & $\begin{array}{l}\text { Siloed court } \\
\text { communities (-) }\end{array}$ \\
\hline \multirow{2}{*}{$\begin{array}{l}\text { Contested } \\
\text { negotiation }\end{array}$} & \multirow[t]{2}{*}{ Legal ambiguity (+) } & Reformative cultures (-) & \\
\hline & & $\begin{array}{l}\text { Conflicting assumptions of } \\
\text { decision-making power (+) }\end{array}$ & \\
\hline
\end{tabular}

Source: Authors' tabulation.

iors to accommodate changes without substantial disruption to courtroom activities. We found passive acceptance occurred when the necessary changes in the law were already part of a court's routine activity or aligned with the legal culture of that court. This allowed actors to accept changes without the need for extensive discussion. Passive acceptance also occurred whenever court actors simply deferred to the interpretation of individuals in a higher position of power. This was most common when prosecutors deferred to the interpretation of judges, although in some cases judges deferred to plea agreements and left it to the attorneys to figure out how to apply the legal changes correctly.

\section{Factors that Affected \\ Sensemaking Processes}

Whether court actors passively accepted, collaboratively interpreted, or contested legal changes depended on the interrelation between a variety of regulative, normative, and cultural features at both the local and state level. Taken together, all of these factors shaped the sensemaking process and how legal changes were ultimately implemented. This highlights the need to consider these factors together when understanding how change becomes disjointly applied across and within criminal legal systems. Table 3 provides a sum- mary of the findings that follow, showing how these influences promote or hinder the specific sensemaking processes that we have identified.

\section{Regulative: Regulatory Oversight and Statute Clarity}

Auxiliary agencies often provided clarity and guidance on the role of monetary sanctions. Their presence in daily court actions varied considerably, however. Because the legal changes in Missouri were written in response to previously low oversight of municipal courts, the state's judicial regulatory bodies ensured a great deal of supervision in regard to the implementation and diffusion of new laws and procedures, especially at the municipal level. In addition to providing standardized information on the expected dollar amounts for court costs in a given case, Missouri's Office of State Court Administrators organized annual conferences that brought together court actors from across the state. These events provided an opportunity for statewide collaboration between OSCA and local courts. This led to greater "organizational coupling" across different court systems whereby practices more closely matched broader institutional policies (Meyer and Rowan 1977). OSCA's extensive guidance via organizing professional forums and providing an explicit space for collaborative interpretation worked to formalize the process of raising 
and addressing questions of ambiguity. Although OSCA may not have been active in every courtroom, this collaborative space was used to incentivize conformity and clarify ambiguity.

Missouri's regulatory body also had a history of policing courts over policy violations. Court actors in Missouri cited instances when regulatory bodies would step in to ensure that courtroom actions were being implemented according to their expectations. A municipal judge in Missouri, who sat on a committee organized by the Missouri Supreme Court, described the corrective actions taken to identify and contest misapplications of law. This passage illustrates the judiciary's role in contesting local-level processes. More specifically, the committee identified potential misapplications of revised license suspension rules and provided a corrective process to ensure that those subject to fines and fees would not be suspended for nonmoving violations:

and when Ferguson came around I went to the fine and collection people and I went to the director and said, "Hey, if this is happening you're going to go through there and you're going to look and see anything that's coming in here and pull it out on the state court level." We found some places where there were seat belt violations and some of that and we went through and you pull all those suspensions out. If it's not a moving violation you do it. We still occasionally have ... I just corrected one this morning. We found one where a seat belt had a suspension. I called up there. It's not a problem anymore because they've become much more aware of it and stuff.

So although regulatory agencies helped to create space for interpretation of the new laws, they also applied regulatory coercion to help ensure conformity and passive acceptance of legal change. This is in contrast to Washington State. Instances of collaborative sensemaking were cited in Washington, especially by judges who attended regular meetings in their local jurisdictions and statewide meetings set up by the Administrative Office of the Courts. However, our participants did not discuss any heavy regulatory action that took place to ensure that legal changes were being enacted correctly. This is not to say that regulation was lacking, but that it lacked the intensity we found in Missouri. ${ }^{12}$ The absence of such a strong regulatory body in the state of Washington may explain why court actors were less likely to cite broader instances of collaborative sensemaking across different courts compared to Missouri.

In addition to regulatory oversight, the clarity of new regulations affected how court actors negotiated and accepted legal changes. Court actors often articulated a passive acceptance of statues that were beyond their control. We observed more variation in the imposition of court costs when the laws were less clear or in opposition to other laws. In Washington State, contestation often occurred around the fines associated with driving under the influence (DUI) charges. When changes in the law made it a requirement for indigent individuals to have all nonmandatory fines and fees waived, interviews and observations indicated that court actors were unsure whether this meant that DUI-specific fines and fees were seen as waivable or were mandatory. A defense attorney in Washington told us that judges would choose between the conflicting laws based on their views of what the laws should be:

INTERVIEWER: Do the amounts vary by the judge?

DEF ATTN: In district court more it does because there's a lot more discretion with the DUI stuff. Also, the prosecutors on those, for some reason, those are the cases where you really see, "Well, we want a \$500 fine," seemingly for no reason. Sometimes, the judge will split the baby. Ever since, I think more recently with Ramirez and Blazina, the judges are just saying, "I'm not imposing fines on this person." ... Or they'll say that Blazina doesn't matter, we agree to the terms of the plea agreement so we're going to impose it. 
INTERVIEWER: Why do you think they vary? What kind of factors lead to variation?

DEF ATTN: I think there's a lot. I think some judges just simply don't care. I think they know what the law is, and they don't care. They'll say this on the record, "Appeal me. I know this is reversible. Appeal me." They know a lot of our clients don't have the time and money and energy to go through that and they know that they're never going to get appealed. It could be that. I think a lot of times, the judges are just not reading the law like they should be. I think they think they're doing what is the law, but they're not actually. I think those are probably the two biggest variations, either not caring or not knowing.

Although defense attorneys protested these DUI-specific LFOs, ambiguity allowed for the judge's interpretation to be implemented. Our findings suggest that the very nature of the revised statutes, and their interplay with previously established court norms, influenced how courts adapted to legal change.

\section{Normative: Local Normative Orders and Macro-Myth Incongruence}

The local sensemaking process of each court was also affected by each court's normative conditions. In particular, we found three factors that appeared particularly salient: the court's orientation toward monetary sanction reform efforts, ideas about who had the power to interpret new laws and implement legal changes, and the congruence between efforts to uphold justice and run an efficient criminal legal system. We expand on each of these factors and describe how they affected acceptance or opposition to the new laws.

In both Washington and Missouri, actors described certain local court cultures as being oriented toward the purpose of the revised statutes before they were put into place. Actors in these courts told us that they had informally adjusted their courtroom practices in a way that aligned with the reforms before the formal legal change and that they liberally waived nonmandatory fines and fees for most defendants. The legal change observed in Washington, for instance, mirrored existing normative expecta- tions and orientations in at least one superior court. Both judges and attorneys we interviewed in that court suggested that the adoption of monetary sanction reforms went more smoothly than in other counties because they were already engaged in many of those practices. Such examples were also evident in Missouri. In an interview with a Missouri judge, they indicated that their court had not incarcerated anyone for failure to pay prior to the legal change barring the use of jail for nonpayment: "Honestly, we didn't change a lot with the reform. We didn't put people in jail for failure to pay for it, we brought them back on show cause [hearings]. We've always done pay agreements since I've been here and before I got here. The forms were already in place. We've done pay agreements."

Overall, the degree to which legal changes aligned with the normative culture of the courts determined how easily those courtroom communities were able to implement these changes. As the data show, conformity with the law was sometimes achieved even before changes in the law itself.

By contrast, one of the key barriers to a uniform court orientation toward monetary sanctions appeared to be generational differences on the judge's bench, which often contributed to contested negotiation of the new laws. One public defender told us that changes in the Washington State statutes were sometimes met with hostility by the "old guard":

There is one judge that we have that's retiring in one or two months. He's hesitant to change. I mean to me it's a very simple thing that I'm asking the judge to do. In my opinion, I'm asking the judge to follow the law. But I guess I don't have the same perspective as somebody that's maybe been on the bench for thirty years. There's an ego there.... someone is telling them that you can't do something that they've [been doing] for thirty years. ... I think the amounts of LFOS and the habits. The presiding judge is really hesitant to waive warrant costs that have been processed like the processing fee for warrants. It's $\$ 100$ for each warrant. The presiding judge, she is hesitant to waive those. And so if I'm before her, I'll make a specific mo- 
tion. I will explain how my client qualifies as indigent and how those costs must be waived. If it's the younger judge, the newest one on the court, I don't need to make that motion. He'll just do it on his own.

In this example, the attorney notes that habits played a significant role in how the judiciary approached monetary sanctions. Consistent with other established processual orders, we found that public defenders adjusted their actions to remedy the disconnect between the spirit of the new statutes and the reality that judges are primarily the powerbrokers in court. We suspect that this dynamic likely plays out differently across courtrooms depending on the extent to which other court actors subscribe to the power dynamics and normative policies around conflict.

An important consideration for court actors was whose role it was to interpret and enforce certain legal practices. We found a consistent pattern of adjusting behaviors based on the normative expectations of judges' power. This was especially true in the probation and parole court community. When asked whether probation revocation was pursued for unpaid fines and fees, a probation officer in Missouri noted, "We used to write a violation report for any individual that still had an outstanding court cost balance. And sometimes judges would take action on that. And we didn't want that happening, but they did. So, our department kind of changed our expectations related to that."

Such practitioner views illustrate how expectations of judicial behavior shaped community supervision decisions, and subsequently shaped the experience of the defendant. Established expectations and processual orders were also evident in Washington where one judge noted that in-court challenges to LFOs are relatively rare. A second judge also indicated that as attorneys become more familiar with the common practices in the court and the "judge's tendencies," they can adjust their expectations around monetary sanctions: "I think, once any attorney, any prosecuting authority, knows the judge, they'll know the judge-what their tendencies are, what they tend to impose, what they don't tend to impose, right? And they'll, if they're smart, would adjust to that."
Although the quoted actors reported the established processual orders as a pathway to bypass conflict (passive acceptance), conceptions about who held power in the courts could also generate conflict in court proceedings. We found this to be true in Washington and Missouri, where court actors' interpretation of legal changes regarding waiving LFOs for indigent defendants would come into conflict. In one Washington court, a public defender explained that judges regularly assume that plea recommendations align with law. Such judges would not hear arguments from public defenders when they pushed back:

And in their [prosecutor's] manual, they've got something in there that says they have to at least ask for \$350 in a first time DUI charge. They just always do. And most prosecutors will not budge on waiving that, cause they're just like, "It's in the manual" and that's the end of the story. And a lot of prosecutors will say, "Well, the judge could waive it if he wants to". And this is where it kind of gets into this, the judge is like, "Well, it's an agreed recommendation. You agreed to it." And I'm like, "Yes, because of the case law that says ultimately you decide. And the prosecutor relied on you ultimately deciding."

In this example, the general flexibility around who is responsible for upholding particular statutes in a discretionary setting creates an inevitable conflict. This finding was reinforced in other interviews where court actors under the same state system had no consensus regarding the responsibility of ensuring equality under the law for the defendant, especially in response to new directives.

A few judges across jurisdictions claimed that attorneys were the ones who needed to be the most informed about changes and it was the attorney's responsibility to negotiate plea deals that complied with any recent changes in the law. However, judges maintained discretion in sentencing, which created some contested negotiations in open court where prosecutors or defense attorneys would argue over how the new laws should be practiced. In St. Louis City, a public defender explained that it was often best to argue in court over fines and fees and 
bypass plea negotiations (pursuant pleas) because judges were more amenable to waiving LFOs than prosecutors.

St. Louis City is notorious for looking at all the priors, and believing that each sentence has to gradually increase, or become more punitive without respect to what actually happened in the case itself and what kind of harm was done. In our jurisdiction, it actually works out much better to open plea or blind plea. I think I've had maybe five pursuant pleas in the entire time that I've worked in that office, just because [prosecutors] make terrible recommendations. That, and then the judges are almost always more willing to cut people a break, especially with regard to monetary amounts, because they're more realistic.

We saw this tactic play out in court both in Missouri and Washington State, where public defenders would argue with judges to waive LFOs in open court, citing the recent changes in law.

The ability of strong court norms to facilitate the anticipation of other actors' decisions developed in other Missouri courts as well. At the county level, judges indicated that state prosecutors knew how much wiggle room they had from the judge in terms of sanction variations. Relatedly, the judge mentioned the outcomes in the court, once established, were relatively stable across cases. Likewise, defense attorneys would anticipate the going rates for particular types of crime. In such cases, they would not engage with the prosecutor to negotiate or contest the norms around sentencing.

Finally, interactional sensemaking was expressed differently depending on the level of tension between reform ideals and the procedural realities of the statutes. Broad courtroom workgroup goals such as expediency and efficiency contributed to passive acceptance of legal changes whenever those changes did not conflict with court processing. One judge in Washington explained: "There's this inherent pressure in our system to be fast, right? To do as many hearings as we can in the shortest amount of time, but you don't want to sacrifice, obviously, doing things right because of that.
But at the same time, you want to recognize the pressures on judges of trying to be efficient." During courtroom observations, these interviews confirmed what we noted as quick conversations around ability to pay that felt superficial and the routine waiving of nonmandatory LFOs.

Where considerations of willful nonpayment were concerned, actors in Missouri cited the additional administrative requirements as being in conflict with efficient case processing. Judges, prosecutors, and court clerks reported that the additional steps needed to find a defendant in violation of nonpayment shaped their behaviors as they were often not worth the extra effort:

You gotta get them an attorney. I think the prosecutor has to be appointed. You gotta appoint the prosecutor and it's the prosecutor's job to prove if they have the ability to pay. I don't think the court engages. I've never engaged. I mean, sometimes . . . we're humans and honestly, do you sit there and make assessments and what you think? I think that's part of figuring out if someone's indigent. Yeah. You sit there and go, hmmm. And I look, did they post bond in three other courts. Well, that goes to say ... I look at that, yeah.

As this prosecutor related, the additional barriers to ensure constitutionality, when combined with cultures of efficiency, produced more informality around willful nonpayment. One county judge in Washington echoed this sentiment and further described the full range of labor that would be incurred:

It'd have to be a show cause or violation of probation for me to do that. I would never do it just for. . . . Judges don't have time to mess with costs. We're not looking at costs. We're not looking at costs and fees. We don't have time for that. We're moving on to the next case. If somebody doesn't pay, we're not going to investigate it or put a bench warrant out on them. And the prosecutors don't care whether costs get paid or not, so you got to sit there and start thinking, "Who's making the application for bench warrants?" Judge 
isn't going to do it on his own. He doesn't have the amount of time in the day to even go to the restroom.

The cultural goal of efficiency held across courtrooms of all levels and sizes, although municipal court actors expressed this sentiment more regularly. The examples suggest that efficiency largely worked in the defendant's favor, but municipal court actors in Missouri also highlighted the conflict of expediency even with the opportunity to informally discuss ability to pay with defendants: "Municipal court is a time-constrained business anyway. You see a lot of people. A lot of times part-time judges and you see a lot of people during that time. So, when there's a lot of administrative stuff, and we file a lot of compliance notices, which is good that we're complying, but that takes time away from doing ... the other things, the more engaging things. Having those conversations and doing some of that."

Overall, the legal changes in Missouri and Washington, which increased the standards of fact-finding for the courts, sometimes clashed with the broader organizational goal of efficiency. In response, actors essentially complied with the law by avoiding the precursors that would require additional engagement with the new statutes. Alternatively, in some spaces fines could still be distributed inequitably and where the goal of expediency overrode values of the revised statutes, even if actions were technically compliant.

\section{Cultural-Cognitive: Professional Silos in Court Communities}

Organizational coupling among court actors was often tightest within each profession because individuals with shared tasks and goals are the most likely to interact and develop expected practices (Eisenstein, Flemming, and Nardulli 1988). Here we consider the accepted organizational structure of modern U.S. court systems. Different agencies working together as a legal community is a cultural expectation for criminal justice. Such a construction outlines the expected cultural template for what a court should look like, what roles actors play within it, and expected scripts for action. This includes an inherent siloing of different professions that share information primarily within their own agencies. We found that such professional siloing had a significant impact on sensemaking within our court systems.

Court actors noted that most of their interpersonal conversations occurred within their own sponsoring agencies. For judges, this occurred at periodic judge's meetings or through statewide professional judges organizations. As a St. Louis judge noted, "Yeah. I just had lunch with a judge today, we were talking about LFOs, as a matter of fact, and how we ... the financial burden that it causes people. It's something that's talked about. When our court, when the judges meet for our monthly meeting, municipal court reform comes up. Typically, it's always something that, because our presiding judge is responsible now, for the supervision of all the municipal courts, he gives us input on how that's going."

Some court actors in Washington also told us that judges met regularly to discuss daily operations of the court and how recent legal changes might impact their practice. These meetings provided a regular opportunity for collaborative meaning-making across judges within the same court network.

Information dissemination for other court actors also flowed primarily within their own agencies. Defense attorneys mentioned receiving information, notices, or training on recent legal changes from their offices. It also appeared that each defense attorney's office tried to create a unified message around the new changes and defense attorneys would advocate for this interpretation in court. Prosecutors also mentioned that changes in the law were communicated through their office. In one Washington State county, prosecutors followed written guidelines disseminated by the local prosecutors office. These guidelines were more rigidly structured and often changed without direct argument. Importantly, despite the presumed guidance of higher-level bodies, mention was still made of deviation based on individual prosecutor's orientations.

Communication was common within professions, but contact across professional channels was less so. For example, one public defender in Washington discussed the barriers to 
communicating with judges in lower-level courts:

I don't have as much access as I would like to have to the judge. You can't just walk to the door and knock and ask for their opinion or anything like that. I hear that used to be different twenty years ago or something. Right now, I don't have as much access as I want. They kind of keep the judges away from us in district court. Even more so than I realize in superior court. I think the superior court attorneys are able to have a little bit more access to the judges. Like they're able to ring for them, present a motion, and have access to them at any time. Oftentimes we write motions, we want it signed, we want a judge's opinion on it right away. Superior court attorneys can do that. I can't. And so, for me, clerks are my gateway to the judge. Often, I use the clerks to know ... they kind of give me clues as to what the judge is thinking or what the judge wants out of a certain situation.

As the attorney noted, accessibility and interaction across courtroom workgroups varied at the jurisdiction level, where local power dynamics contoured interactions. Several court actors emphasized deference to the judge, and rather than attempts to negotiate through contestation, the general impetus was to anticipate the judicial decision-making process. Thus, at the courtroom workgroup level, passive acceptance manifested in contexts that were especially disconnected and where actors rarely interacted in any formal way outside of the courtroom. Such settings allowed for individuals to shift sensemaking of legal change and other responsibilities to other actors.

We also highlight two important counterexamples. In one Washington State superior court, we found a unique instance of collaborative interpretation where legal change spurred discussions and coordination between court actors. More specifically, a superior court clerk told us that prosecutors, public defenders, and clerks had come together to discuss how they planned to enact the new requirements for assessing future ability to pay and dealing with payment compliance. They agreed to monitor compliance in a more informal way: a public defender and the superior court clerk would meet with folks who stopped making monthly payments and talk through a plan to get them back on track and almost always resulted in more time to comply with payment orders.

Our conversations with Washington defense attorneys also told us that they would write briefs in response to what they believed were judicial misinterpretations of the new statutes. They believed these briefs would be discussed at monthly judge's meetings. As one attorney explained, "The judges have a regular meeting amongst themselves and often discuss certain subjects. And so, I know that in the past we've brought issues to them, which include things like, 'Hey, you're not using your discretion with regard to fines.' And that gets discussed amongst the judges. And sometimes after one of those meetings, you will see the judges do things appropriately because we brought it to their attention that it's not been effectuated properly."

Although this appeared to be a way for information to be discussed across types of decisionmakers, the process of interpreting these briefs and drawing conclusions was reserved for judges. Rather than collaboratively interpreting legal change, public defenders in Washington contested judges' interpretation either in court or through these formal briefs. There were not common processes across our observations for court actors of different professions to regularly meet collaboratively within any given court district in Washington State.

\section{Summary}

The importance of contextual factors in determining the course of interpreting and implementing changes to monetary sanction laws in Missouri and Washington State is clear. One of the biggest factors, and one that differed the most between the two states, was the presence of a strong regulatory entity. The political salience of LFOs in Missouri meant that the legislature was particularly motivated to ensure a large degree of conformity across jurisdictions in the wake of legal changes. The OSCA effectively provided standardized information at all court levels, offered training of court actors 
during annual conferences, and implemented corrective actions when necessary. These actions limited the sensemaking needs of court actors because they were provided clarity on how to interpret the new laws and directive actions on how to implement new practices. Thus Missouri courts were much more likely to engage in a collaborative process of discussing the new laws and passive acceptance of changes that OSCA dictated to them. This differed from Washington, where regulatory oversight was not as stringent. In Washington, the integration of legal changes into practice was mostly left up to the individual jurisdictions. Although collaboration and passive acceptance did occur, when court actors had differential interpretations of the law, it was more likely for legal changes to be contested in Washington.

Despite the presence of higher regulation in Missouri, the legal structure did not guarantee conformity across all jurisdictions. We still found that the sensemaking process was influenced by other important factors and that many of these factors were found to be important in similar ways within both states. Sensemaking was affected based on how well the laws aligned with the previously established context of the courts. This especially related to the localized court culture of each jurisdiction. Because these new monetary sanction laws were based on reform efforts, we saw jurisdictions in both states described as more liberal or reform-oriented engage in greater collaboration and acceptance of legal changes. In courts described as less reform oriented, contestation and disagreement between court actors was much higher. In other words, whenever local court cultures were oriented toward the legal changes, actors often passively accepted those changes as a matter of course. We also saw greater contested negotiation when the laws were either in conflict with previously established laws or perceived as ambiguous. Ambiguity in the new laws led to confusion by court actors over how to implement the new required practices and who was responsible for keeping track of these changes. When ambiguity was high, our interviewees were more likely to indicate instances of contested sensemaking and disagreement. Finally, actors also engaged in a kind of passive change of practice in order to align new practices with established norms of case processing to keep courts operating in an efficient and uniform manner.

The sensemaking process was also affected by the larger organizational configuration of U.S. courts. In both states, collaboration across court professions was the exception. Although we found instances of within-profession interpretation of new laws (such as judges talking to judges, defense attorneys talking to defense attorneys), efforts to engage across professional lines outside the courtroom itself appeared rare. Thus, although our understanding of courtroom communities can help us investigate how court actors from different agencies engage in courtroom practice, it can also point us to the ways in which this legal structure inhibits the flow of information and collaboration within the larger court context.

Overall, we found important factors that shaped congruence both across and within our two states. The presence of a stronger regulatory institution led to greater conformity across courts within Missouri compared to Washington. However, courts within Missouri still showed levels of disagreement on the implementation of new laws. Within both Missouri and Washington, we found the process of interpreting and implementing new laws to be impacted by the different organizational, normative, and cultural configurations of each court.

\section{DISCUSSION}

In this article, we examine the processes by which court actors interpreted, negotiated, and implemented new legal practices following changes to monetary sanction laws in Missouri and Washington. We find that this sensemaking generally took one of three forms: actors accepted changes to practice as a matter of course or in automatic response to the actions of other actors (passive acceptance); actors engaged in opportunities for collective and collaborative interpretation and discussion of legal changes (collaborative interpretation); and actors engaged in contested forms of disagreement, argumentation, or negotiation over the interpretations or actions of other actors (contested negotiation).

We also identify an assortment of institutional factors that shaped, helped, or hindered 
these processes in key ways. We especially highlight the importance of regulatory oversight in determining greater courtroom conformity in Missouri relative to Washington. However, the stated goals of new legal mandates did not always translate to clear changes in courtroom behaviors or perspectives in either state-even when strong regulative features were imposed. Across our study sites in both states, we find that normative and cultural-cognitive features informed the nature and extent of interpretation. How these factors shaped the interpretative process proved to be consequential in determining congruence with changing policies. Consistent with other work on this project (such as Kirk et al. 2022, this volume), we find that the localized nature of courts and their communities are consequential to the success of broader changes to monetary sanction policy.

Overall, this study demonstrates the viability of understanding courts as inhabited institutions. Such a perspective helps us highlight the importance of organizational and institutional factors in determining legal outcomes. The ways in which new laws are passed, how information about those laws are disseminated, and how new policies are regulated help to determine courtroom activity. Of course, an essential aspect of the inhabited institutions perspective is in emphasizing ground-level action. Although stricter oversight of monetary sanction practices led to more consistency, the implementation of these laws clearly went through localized interpretative activity in both states. Court agencies, workgroups, and individual actors all engaged in strategic responses to new laws and engaged in an interactive process of meaning-making with other court entities to facilitate (or hinder) practical change. Such findings are consistent with Karin Martin, Kimberly Spencer-Suarez, and Gabriela Kirk (2022, this volume), which suggests that fidelity to local norms informs how punishment is applied, and where opportunities for discretion occur. In their work, cultures of defendant accountability among court actors engendered attention toward how long it might take to pay a sanction, even though regulatory frameworks largely emphasized assessments of inability to pay at all. Ulmer's suggestion that "courts are governed by institutional rules and laws but are inhabited by courtroom workgroup actors with agency and court community organizations with their own informal norms, culture, politics, and constraints" is thus crucial for identifying how disparities emerge, even when mandates and reforms are in place $(2019,493)$. This organizationally oriented perspective underscores the importance of both the decisionmaking of street level actors and the range of multilevel variables that influence their actions.

We believe our approach offers a unique perspective, but recognize the key limitation that our study only compares and contrasts two states. A wider examination of states, and the changes they introduce to the courtroom, would further clarify the impact of the factors we have described. Future work would yield important insights with a more robust comparison of legal frameworks across states and jurisdictions. In Missouri, the changes to LFO laws came primarily from legislative action with plenty of regulatory oversight and a greater sense of political pressure. By contrast, changes in Washington occurred first through case law and Supreme Court decisions, and only later were LFOs reformed through a legislative bill. This is not to say that Missouri lacked discretionary influence or that Washington lacked regulatory oversight, but that the origin of legal change in Missouri and Washington differed in ways that may have shaped sensemaking processes. Furthermore, although previous work using the court community framework has explored contextual factors that help foster cross-court uniformity, our findings may indicate that it is the court community structure itself that hinders isomorphism. Although we are limited in our ability to fully investigate the consequences of court structure on case outcomes, emerging evidence from Minnesota links "jurisdictional mazes" with respect to tribal populations to differential case outcomes (Stewart et al. 2022, this volume). Future work should further explore the role of court structures by comparing more federalized states with those that have unified court systems.

All mandates to change courtroom practice, such as those that Brittany Friedman and her 
colleagues propose (2022, this volume), will enter into a transformative process by which new laws are interpreted, negotiated, and implemented in accordance with local sensemaking practices that are in turn shaped by the structure of the court and the context in which it is embedded. Such findings are not only relevant to understanding the translation of legal changes, but also may help explain instances where defendants are subject to different outcomes despite being heard under the same legal mandates (see Kirk et al. 2022, this volume; Stewart et al. 2022, this volume).

From a policy perspective, the findings not only apply to reform efforts, but also are useful for identifying how legal change manifests in practice. Certainly, changes to criminal justice policies are often invoked with reformative language and in hopes of instituting broadscale changes in outcomes. For example, in Missouri, Macks Creek Law was aimed at reducing monetary sanctions as a tool for resource extraction (Huebner and Giuffre 2022, this volume). Yet, as Franklin Zimring notes (2020), the assumption that court actors at the individual level will automatically reorient themselves to align with the broader reform effort is untenable. Instead, our findings show that the interpretation of laws is inherently local and subject to often unmeasured power dynamics. Thus, meaningful alignment between the goals of a legal change and eventual outcomes requires sensitivity not only to the regulatory frameworks that are intended to shape the reform, but also the normative and cultural-cognitive factors that influence their interpretation. In the wake of perpetual legal change, identifying and understanding the relevant characteristics of local courts - particularly in ways not normally captured in traditional empirical analyses-is essential to crafting policies that meet their intended goals.

\section{REFERENCES}

Berger, Peter L., and Hansfried Kelner. 1981. Socially Interpreted: An Essay on Method and Vocations. Garden City, N.Y.: Doubleday.

Berger, Peter L., and Thomas Luckmann. 1967. The Social Construction of Reality. New York: Doubleday.

Clair, Matthew. 2020. Privilege and Punishment: How
Race and Class Matter in Criminal Court. Princeton, N.J.: Princeton University Press.

DiMaggio, Paul J., and Walter W. Powell. 1983. “The Iron Cage Revisited: Institutional Isomorphism and Collective Rationality in Organizational Fields." American Sociological Review 48(2): 14760.

Dixon, Jo. 1995. "The Organizational Context of Criminal Sentencing." American Journal of Sociology 100(5): 1157-198.

Eisenstein, James, Roy Flemming, and Peter Nardulli. 1988. The Contours of Justice: Communities and Their Courts. Boston, Mass.: Little Brown.

Emerson, Robert M, Rachel I. Fretz, and Linda L. Shaw. 2011. Writing Ethnographic Field Notes, 2nd ed. Chicago: University of Chicago Press.

Engen, Rodney L., and Sara Steen. 2000. “The Power to Punish: Discretion and Sentencing Reform in the War on Drugs." American Journal of Sociology 105(5): 1357-395.

Flemming, Roy, Peter Nardulli, and James Eisenstein. 1992. The Craft of Justice: Politics and Work in Criminal Court Communities. Philadelphia: University of Pennsylvania Press.

Fligstein, Neil, and Douglas McAdam. 2011. “Toward a General Theory of Strategic Action Fields." Sociological Theory 29(1): 1-26.

Friedman, Brittany, Alexes Harris, Beth M. Huebner, Karin Martin, Pettit Becky, Sarah K.S. Shannon, and Bryan L. Sykes. 2022. "What Is Wrong with Monetary Sanctions? Directions for Policy, Practice, and Research." RSF: The Russell Sage Foundation Journal of the Social Sciences 8(1): 221-43. DOI: https://doi.org/10.7758/RSF.2022.8.1.10.

Harris, Alexes, Mary Pattillo, and Bryan L. Sykes. 2022. "Studying the System of Monetary Sanctions." RSF: The Russell Sage Foundation Journal of the Social Sciences 8(1): 1-33. DOI: https://doi. org/10.7758/RSF.2022.8.1.01.

Hester, Rhys. 2017. “Judicial Rotation as Centripetal Force: Sentencing in the Court Communities of South Carolina." Criminology 55(1): 205-35.

Huebner, Beth M., and Andrea Giuffre. 2022. “Reinforcing the Web of Municipal Courts: Evidence and Implications Post-Ferguson." RSF: The Russell Sage Foundation Journal of the Social Sciences 8(1): 108-27. DOI: https://doi.org/10.7758 /RSF.2022.8.1.05.

Johnson, Brian D. 2005. “Contextual Disparities in Guidelines Departures." Criminology 43(3): 76197. 
Kirk, Gabriela, Kristina J. Thompson, Beth M. Huebner, Christopher Uggen, and Sarah K.S. Shannon. 2022. "Justice by Geography: The Role of Monetary Sanctions Across Communities." RSF: The Russell Sage Foundation Journal of the Social Sciences 8(1): 200-220. DOI: https://doi.org/10 .7758/RSF.2022.8.1.09.

Martin, Karin D., Kimberley Spencer-Suarez, and Gabriela Kirk. 2022. “Pay or Display: Monetary Sanctions and the Performance of Accountability and Procedural Integrity in New York and Illinois Courts." RSF: Russell Sage Foundation Journal of the Social Sciences 8(1): 128-47. DOI: https://doi .org/10.7758/RSF.2022.8.1.04.

Meyer, John W., and Brian Rowan. 1977. “Institutionalized Organizations: Formal Structure as Myth and Ceremony." American Journal of Sociology 83(2): 340-63.

Myers, Martha, and Susette Talarico. 1987. The Social Contexts of Criminal Sentencing. New York: Springer-Verlag.

Richards, Lyn. 2015. Handling Qualitative Data: A Practical Guide, 3rd ed. Thousand Oaks, Calif.: Sage Publications.

Scott, W. Richard. 2008. Institutions and Organizations: Ideas and Interests. Thousand Oaks, Calif.: Sage Publications.

Spohn, Cassia, and Robert Fornango. 2009. "US Attorneys and Substantial Assistance Departures: Testing for Interprosecutor Disparity." Criminology 47(3): 813-47.

Stewart, Robert, Brieanna Watters, Veronica Horow- itz, Ryan P. Larson, Brian Sargent, and Christopher Uggen. 2022. "Native Americans and Monetary Sanctions." RSF: The Russell Sage Foundation Journal of the Social Sciences 8(2): 137-56. DOI: https://doi.org/10.7758/RSF.2022 8.2.07.

Strauss, Anselm. 1993. Continual Permutations of Action. New York: Aldine de Gruyter.

Ulmer, Jeffery T. 2005. “The Localized Uses of Federal Sentencing Guidelines in Four US District Courts: Evidence of Processual Order." Symbolic Interaction 28(2): 255-79.

_. 2012. "Recent Developments and New Directions in Sentencing Research." Justice Quarterly 29(1): 1-40.

—. 2019. “Criminal Courts as Inhabited Institutions: Making Sense of Difference and Similarity in Sentencing." Crime and Justice 48 (February): 453-582.

Ulmer, Jeffery T., and Brian Johnson. 2004. “Sentencing in Context: A Multilevel Analysis." Criminology 42(1): 137-77.

—. 2017. “Organizational Conformity and Punishment: Federal Court Communities and JudgeInitiated Guideline Departures." Journal of Criminal Law and Criminology 107(2): 253-92.

Van Cleve, Nicole. 2020. Crook County: Racism and Injustice in America's Largest Criminal Court. Stanford, Calif.: Stanford University Press.

Zimring, Franklin E. 2020. The Insidious Momentum of American Mass Incarceration. Oxford: Oxford University Press. 